\title{
Myotomy of Distal Esophagus Influences Proximal Esophageal Contraction and Upper Esophageal Sphincter Relaxation in Patients with Achalasia After Peroral Endoscopic Myotomy
}

\author{
Yutang Ren, ${ }^{1}$ Xiaowei Tang, ${ }^{1,2}$ Fengping Chen, ${ }^{2}$ Zhiliang Deng, ${ }^{2}$ Jianuan $\mathrm{Wu}^{2}{ }^{2}$ Soma Nei, ${ }^{1}$ Bo Jiang, ${ }^{1}$ and Wei Gong ${ }^{2 *}$ \\ ${ }^{I}$ Department of Gastroenterology, Beijing Tsinghua Changgung Hospital, Medical Center, Tsinghua University, Beijing; China; and ${ }^{2}$ Department \\ of Gastroenterology, Nanfang Hospital, Southern Medical University, Guangzhou, China
}

\section{Background/Aims}

The motility change after peroral endoscopic myotomy (POEM) in achalasia is currently focused on lower esophageal sphincter (LES). This study aims to investigate the correlation of motility response between distal and proximal esophagus after POEM.

\section{Methods}

A total of 32 achalasia patients who received POEM and high-resolution manometry (HRM) were included for analysis. Eckardt score was used to assess symptom improvement. HRM was applied for studying motility. Main parameters analyzed were (1) LES: resting pressure (restP), 4-second integrated relaxation pressure; (2) esophageal body (EB): contractile integral of distal segment with myotomy (CI-DM) and proximal segment without myotomy (CI-PNM); and (3) upper esophageal sphincter (UES): relaxation pressure (UES-RP).

\section{Results}

There were 6 type I, 17 type II, and 9 type III achalasia patients included for analysis. (1) Eckardt score, LES tone, CI-DM, CI-PNM and UES-RP were reduced remarkably after POEM $(P<0.001)$. (2) no significant correlation was noted between LES tone and contractile intergral of EB. (3) a positive linear correlation of CI-DM and CI-PNM changes was detected $(P<0.001)$. (4) the change of UES-RP was positively correlated with the change of contractile integral of EB $(P<0.001)$.

\section{Conclusions}

Myotomy of the distal esophagus would attenuate proximal EB contraction and assist UES relaxation in achalasia patients after POEM.

(J Neurogastroenterol Motil 2016;22:78-85)

Key Words

Esophageal achalasia; Manometry; Peroral endoscopic myotomy

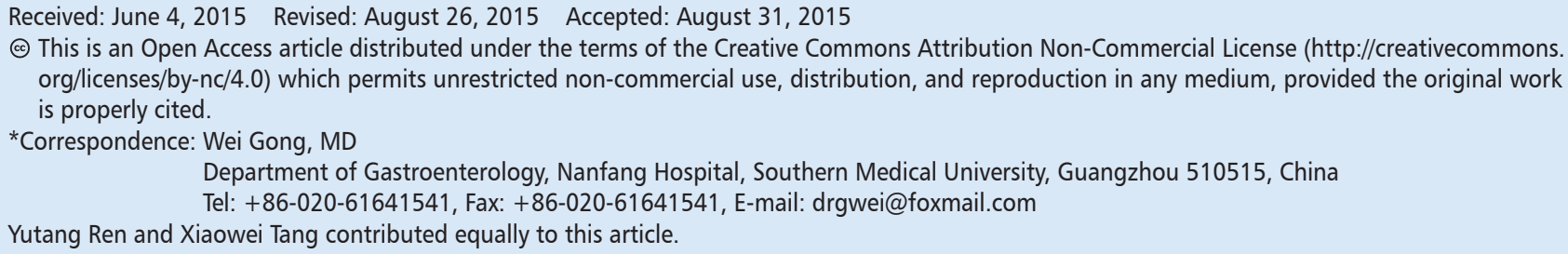




\section{Introduction}

Achalasia is an esophageal motility disorder, which is defined as impaired deglutitive lower esophageal sphincter (LES) relaxation and aperistalsis of the esophageal body (EB). ${ }^{1}$ When achalasia patients swallow food, the dysmotility change would lead to food bolus impaction and food stasis. Thus achalasia patients usually complain of dysphagia, regurgitation, and chest pain, which greatly impairs their life quality. ${ }^{2}$

The emerging peroral endoscopic myotomy (POEM) is a promising and minimal-invasive surgery, which showed even better clinical outcome than pneumatic dilation in the short term. ${ }^{3-5}$ However, investigations on motility change after POEM was mainly focused on LES. In several studies, not only LES resting pressure, but also LES relaxation pressure was noted to be decreased dramatically. ${ }^{3,46}$ This was believed to be the main reason for satisfactory symptom improvement.

Nevertheless, Wauters et $\mathrm{al}^{7}$ reported that the motility change of LES after pneumatic dilation correlated significantly with the change in upper esophageal sphincter (UES) and EB motility in achalasia patients. This finding shed light on the distal therapeutic effect for the proximal esophagus. Yao and Linghu ${ }^{8}$ also reported decreased UES relaxation pressure after POEM, but the exact mechanism was still unclear. So the aim of this study is to investigate the therapeutic effect of POEM on the proximal esophagus, especially in achalasia subtypes.

\section{Materials and Methods}

\section{Study Subjects}

This study is a retrospective analysis of a prospectively collected achalasia database. Thirty-two achalasia patients were included and treated at a tertiary gastroenterology center (Nanfang Hospital, Guangzhou, China) between November 2012 and July 2013. Achalasia was diagnosed by clinical symptoms, barium esophagram, and high-resolution manometry (HRM) with Chicago classification. ${ }^{9-11}$ Endoscopy was used to exclude pseudo-achalasia such as carcinoma of the cardia. Exclusion criteria were patients with coagulopathy, pregnancy, American Society of Anesthesiologists (ASA) stage $\geq 4$, and patients who reject manometry and who withdraw informed consent. Standard Eckardt score was used to evaluate the severity of disease and the efficacy of POEM. ${ }^{12}$ The patients were followed up with both Eckardt score and HRM. The study protocol was approved by the institutional review board of Nanfang Hospital (NFEC-201211-K2) and adhered to the Declaration of Helsinki. Informed consent was obtained from all participating patients.

\section{High-resolution Manometry Procedure}

All patients fasted overnight before HRM, which was conducted using solid-state probe with pressure sensors spaced at $1-\mathrm{cm}$ intervals from the pharynx to the stomach (Sierra Scientific, Los Angeles, CA, USA). The patient was oriented in a left decubitus position. Prior to each recording, the probe was calibrated using externally applied pressure. After an initial equilibration period, the resting pressure was recorded over a 1 -minute period before 10 swallows at 30-second intervals of $5 \mathrm{~mL}$ of water at room temperature. The motility data were recorded and analyzed by Manoscan 360 (Sierra Scientific, Los Angeles, CA, USA).

\section{Peroral Endoscopic Myotomy Technique}

POEM was performed by Dr Wei Gong as described by Inoue et $\mathrm{al}^{3}$ with general anesthesia and $\mathrm{CO}_{2}$ insufflation. First, a submucosal injection with normal saline and indigo carmine were made 5-10 cm above the gastroesophageal junction (GEJ), followed by a $2 \mathrm{~cm}$ longitudinal incision using a triangle-tip knife (KD-640L; Olympus, Tokyo, Japan). Second, the submucosal layer was dissected to make a tunnel along the esophagus and across the GEJ 2-3 $\mathrm{cm}$ into the proximal stomach. Third, myotomy was started 3 $\mathrm{cm}$ below the tunnel entrance and extended $2-3 \mathrm{~cm}$ into the proximal stomach. The circular muscle fiber was dissected and the longitudinal muscle fiber was preserved. Fourth, the submucosal entry was closed by metal clips (EZ-CLIP; Olympus). The esophageal myotomy length was measured above the LES. The gastric length was measured below the GEJ. After the procedure, patients received antibiotics and intravenous nutrition for 3 days, after which they began to take liquid food and gradually changed to solid food. They were followed up with Eckardt scores and HRM 3 months after POEM.

\section{High-resolution Manometry Data Analysis}

\section{Lower esophageal sphincter parameters}

LES resting pressure (LES restP) was assessed before all wet swallows using the LES markers. Impaired LES relaxation was calculated using the 4-second integrated relaxation pressure (4sIRP). LES parameters were determined as the mean pressures for 10 wet swallows of $5 \mathrm{~mL}$ each. 


\section{Esophageal body parameters}

A new parameter, the contractile integral (CI), was used to represent the amplitude, duration, and length of the EB contraction. CI was measured using the software Manoscan in a way similar to the distal contractile integral (DCI): amplitude $\times$ duration $\times$ length $(\mathrm{mmHg} \cdot \mathrm{sec} \cdot \mathrm{cm})$ of the esophageal contraction exceeding $20 \mathrm{mmHg}$ of a given segment. CI was separated according the esophageal myotomy length and total esophageal length between the lower border of the UES and the upper border of the LES. CI of the distal segment with myotomy (CI-DM; Fig. 1A) and CI of the proximal segment without myotomy (CI-PNM; Fig. 1B) were measured for each swallow, which were averaged for each series of 5 $\mathrm{mL}$ wet swallows.

\section{Upper esophageal sphincter parameters}

UES restP were calculated before all wet swallows. The relaxation pressure (UES-RP, the nadir pressure) and relaxation duration were averaged for each series of $5 \mathrm{~mL}$ wet swallows.

\section{Manometric classification for achalasia}

The diagnosis of achalasia was supported manometrically by the Chicago classification for esophageal motility disorders. ${ }^{9}$ Type I achalasia was diagnosed with a mean 4s-IRP over $15 \mathrm{mmHg}$ with $100 \%$ failed peristalsis. Type II achalasia was recognised with 4sIRP over $15 \mathrm{mmHg}$ and panesophageal pressurization present in $\geq 20 \%$ of swallows. Type III achalasia was characterised by 4s-IRP over $15 \mathrm{mmHg}$ and spastic contractions in $\geq 20 \%$ of swallows.

\section{Statistical Methods}

Data from HRM were described as mean \pm standard deviation. Age, Eckardt score, myotomy length, and CI were written as the median value (range). Eckardt score changes were analysed using paired Wilcoxon test. Changes of manometric parameters were compared by Students' $t$ test, except for CI, in which the paired Wilcoxon test was utilized. Spearman correlation analysis was used to identify the possible correlation between motility parameters. A two-sided $P$-value of $<0.05$ is considered statistically significant. Standard statistics software was used (SPSS version 22.0, IBM Co, Somers, NY, USA).

\section{Results}

\section{Information of Achalasia Patients}

The study group was composed of 16 males and 16 females, with a median (range) age of 34.5 (19-68) years (Table 1). Six patients were classified as type I achalasia, 17 patients had type II achalasia, and 9 patients were categorized as type III achalasia. Eleven patients received previous treatments without satisfactory results. All achalasia patients received POEM successfully. The median (range) esophageal myotomy length was $5.0(3-10) \mathrm{cm}$ and the median (range) gastric myotomy length was $3.0(2-5) \mathrm{cm}$. POEM reduced the Eckardt score remarkably (7.5 [4.0-11.0] vs 1.0 [0.05.0], $P<0.001)$ within a median follow-up time of $2.0(1.0-8.0)$ months.
A

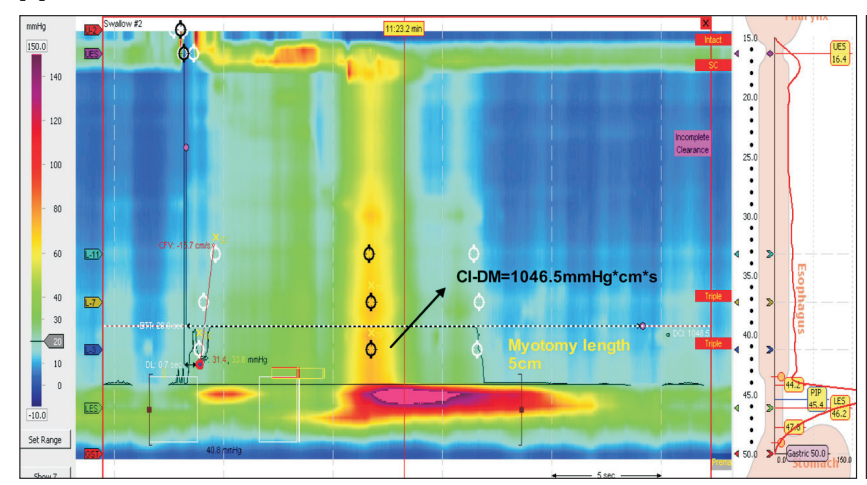

B

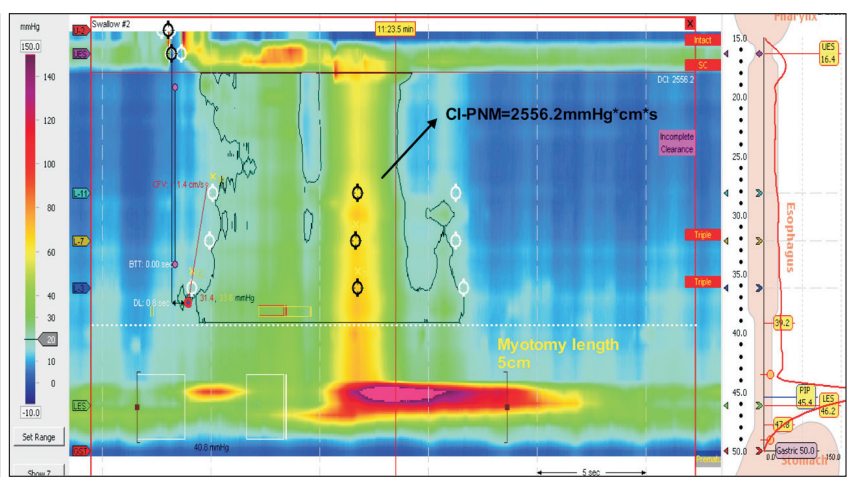

Figure 1. The contractile integral was calculated using the software Manoscan in a way similar to distal contractile integral: amplitude $\times$ duration $\times$ length $(\mathrm{mmHg} \cdot \mathrm{sec} \cdot \mathrm{cm})$ of the esophageal contraction exceeding $20 \mathrm{mmHg}$ of a given segment. (A) Contractile integral of the distal segment with myotomy (CI-DM) was measured in the distal pressurization part outlined in black. (B) Contractile integral of the proximal segment without myotomy (CI-PNM) was measured in the proximal pressurization part outlined in black. 


\section{Treatment Effects on Esophageal Motility}

LES motility parameters such as restP and 4s-IRP were reduced significantly after POEM (38.12 \pm 13.48 vs $14.53 \pm 4.92$ $\mathrm{mmHg}, P<0.001$ and $31.28 \pm 10.03$ vs $8.80 \pm 4.22 \mathrm{mmHg}$, $P<0.001$; Table 2). POEM lowered the CI of EB contraction significantly in both distal segments with myotomy and proximal segments without myotomy (CI-DM: 43.95 [0.29-743.40] vs 3.79 [0-665.70] mmHg.sec $\cdot \mathrm{cm}, P<0.001$; CI-PNM:1337.73 [2.309856.31] vs 480.85 [2.16-3121.83] $\left.\mathrm{mmHg} \cdot \mathrm{sec}^{\circ} \mathrm{cm}, P<0.001\right)$. The UES relaxP was reduced by POEM (12.74 \pm 7.14 vs 5.79

Table 1. Information of Recruited Achalasia Patients ( $\mathrm{N}=32)$

\begin{tabular}{lc}
\hline \multicolumn{1}{c}{ Male/female ratio } & $16 / 16$ \\
\hline Age (median [range], yr) & $34.50(19-68)$ \\
Chicago classification: Type 1/2/3 & $6 / 17 / 9$ \\
Previous treatment (No. of patients) & 9 \\
$\quad$ Pneumatic dilation & 2 \\
Botox injection & 0 \\
Heller myotomy & \\
Eckardt score (median [range]) & $7.5(4-11)$ \\
Before POEM & $1.0(0-5)^{\mathrm{a}}$ \\
$\quad$ After POEM & \\
Myotomy length of POEM (median [range]) & $5.0(3-10)$ \\
$\quad$ Esophageal & $3.0(2-5)$ \\
Stomach & \\
Adverse events (No. of patients) & 2 \\
Subcutaneous emphysema & 1 \\
Pneumothorax & \\
\hline
\end{tabular}

${ }^{a}$ Level of significance, $P<0.001$.

POEM, peroral endoscopic myotomy. $\pm 6.11 \mathrm{~cm}, P<0.001)$. However, $\mathrm{UES}$ restP and relaxation duration remained almost unchanged. In subtypes according to Chicago classification, LES restP and 4s-IRP were all reduced remarkably in type I, type II, and type III achalasia (Supplementary Table). The reduction of CI-PNM, CI-DM, and UES-RP were significant in type II and type III achalasia, but were insignificant in type I achalasia. It should be noted that sample size in type I achalasia is small.

\section{The Correlation of Changes in Motility Parameters Between Distal Esophagus with Myotomy and Proxi- mal Esophagus Without Myotomy After Treatment}

After POEM, no significant correlation was detected between the change of LES restP, 4s-IRP and the motility parameters of EB and UES (Table 3). There was a positive linear correlation of $\mathrm{CI}$ changes between the distal EB segment with myotomy and proximal EB without myotomy (correlation coefficient $=0.901$, $P<0.001$; Fig. 2). The change of UES-RP was positively correlated with the $\mathrm{CI}$ of distal $\mathrm{EB}$ with myotomy and proximal $\mathrm{EB}$ without myotomy (CI-DM: correlation coefficient $=0.705, P<$ 0.001; CI-PNM: correlation coefficient $=0.755, P<0.001)$.

\section{Different Correlation Patterns in Achalasia Subtypes After Treatment}

In type I achalasia, no significant correlation of changes was detected between CI-DM, CI-PNM and UES-RP (Table 4). In type II achalasia, there was a significant positive correlation of changes between CI-DM and CI-PNM (correlation coefficient $=0.699, P=0.002)$, CI-PNM, and UES-RP(correlation coefficient $=0.691, P=0.002)$. However, the correlation between

Table 2. The Effect of Peroral Endoscopic Myotomy on Esophageal Motility ( $\mathrm{N}=32)$

\begin{tabular}{lccr}
\hline \multicolumn{1}{c}{ Motility parameters } & Before POEM & After POEM & $P$-value \\
\hline LES & & & $<0.001$ \\
restP $(\mathrm{mmHg})$ & $38.19 \pm 13.48$ & $14.53 \pm 4.92$ & $<0.001$ \\
4s-IRP $(\mathrm{mmHg})$ & $31.28 \pm 10.03$ & $8.80 \pm 4.22$ & $<0.001$ \\
EB & & & $<0.001$ \\
CI-PNM $(\mathrm{mmHg} \cdot \mathrm{sec} \cdot \mathrm{cm})$ & $1337.73(2.30-9856.31)$ & $480.85(2.16-3121.83)$ & \\
CI-DM $(\mathrm{mmHg} \cdot \mathrm{sec} \cdot \mathrm{cm})$ & $43.95(0.29-743.40)$ & $3.79(0-665.70)$ & 0.946 \\
$\mathrm{UES}$ & & & $<0.001$ \\
restP $(\mathrm{mmHg})$ & $83.91 \pm 34.08$ & $5.87 \pm 35.48$ & 0.709 \\
RP $(\mathrm{mmHg})$ & $12.96 \pm 7.30$ & $817.16 \pm 168.23$ & \\
RD $(\mathrm{msec})$ & $828.25 \pm 194.81$ & & \\
\hline
\end{tabular}

POEM, peroral endoscopic myotomy; LES, lower esophageal sphincter; restP, resting pressure; 4s-IRP, 4-second integrated relaxation pressure; EB, esophageal body; CI-PNM, contractile integral of proximal segment without myotomy; CI-DM, contractile integral of distal segment with myotomy; UES, upper esophageal sphincter; RP, relaxation pressure; RD, relaxation duration. 
Table 3. Bivariate Spearman Correlation Analysis of Motility Changes ( $\Delta$ change After Peroral Endoscopic Myotomy) Between Lower Esophageal Sphincter Tone, Esophageal Body Contraction, and Upper Esophageal Sphincter Relaxation

\begin{tabular}{|c|c|c|c|c|}
\hline \multirow{2}{*}{\multicolumn{2}{|c|}{ Items }} & \multicolumn{2}{|c|}{ EB } & \multirow{3}{*}{$\begin{array}{c}\text { UES } \\
\Delta \text { UES-RP } \\
0.186\end{array}$} \\
\hline & & \multirow{2}{*}{$\frac{\Delta \mathrm{CI}-\mathrm{DM}}{0.135}$} & \multirow{2}{*}{$\frac{\Delta \mathrm{CI}-\mathrm{PNM}}{0.188}$} & \\
\hline$\Delta \mathrm{LES}$ restP & Correlation coefficient & & & \\
\hline & $P$-value & 0.462 & 0.304 & 0.308 \\
\hline \multirow{2}{*}{$\Delta \mathrm{LES}-\mathrm{IRP}$} & Correlation coefficient & 0.329 & 0.298 & 0.186 \\
\hline & $P$-value & 0.066 & 0.098 & 0.308 \\
\hline \multirow[t]{2}{*}{$\Delta \mathrm{UES}-\mathrm{RP}$} & Correlation coefficient & 0.705 & 0.755 & \\
\hline & $P$-value & $<0.001$ & $<0.001$ & \\
\hline \multirow{2}{*}{$\Delta \mathrm{CI}-\mathrm{PNM}$} & Correlation coefficient & 0.901 & & \\
\hline & $P$-value & $<0.001$ & & \\
\hline
\end{tabular}

EB, esophageal body; UES, upper esophageal sphincter; CI-DM, contractile integral of distal segment with myotomy; CI-PNM, contractile integral of proximal segment without myotomy; UES-RP, relaxation pressure of UES; LES, lower esophageal sphincter; LES restP, resting pressure of LES; LES-IRP, integrated relaxation pressure of LES.

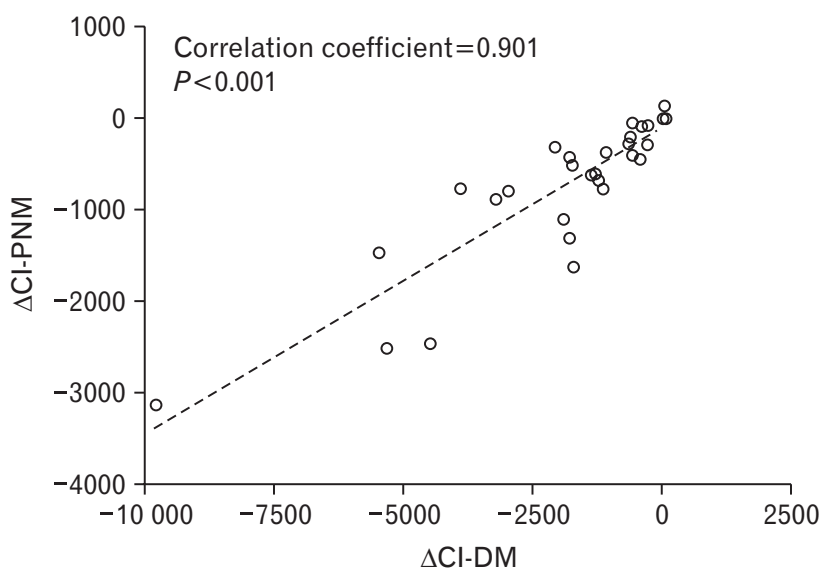

Figure 2. Linear correlation of changes $(\Delta)$ of contractile integral between the distal segment with myotomy (CI-DM) and proximal segment without myotomy (CI-PNM).

CI-DM and UES-RP was insignificant (correlation coefficient $=$ $0.400, P=0.112$ ). It could be observed that the pressurization of the EB changed synchronously as a whole, irrespective of segment with myotomy or without myotomy (Fig. 3A and 3B). In type III achalasia, the positive correlation of changes in $\mathrm{CI}$ was significant between the distal $\mathrm{EB}$ with myotomy and proximal $\mathrm{EB}$ without myotomy (correlation coefficient $=0.917, P=0.001$ ). However, insignificant positive correlations could be detected between CI-DM and UES-RP (correlation coefficient $=0.667, P=0.050$ ), CI$\mathrm{PNM}$ and UES-RP(correlation coefficient $=0.650, P=0.058$ ). It could also be observed that the spasm in the proximal segment without myotomy attenuated with spasm in the distal segment with myotomy after POEM (Fig. 3C and 3D). The sample size in type
III achalasia was also relatively small.

\section{Discussion}

In this study, significant positive correlations were observed between the changes of contraction pressure of distal EB with myotomy, contraction pressure of proximal EB without myotomy and UES-RP after POEM. This finding suggested that myotomy of the distal esophagus could influence contraction of the proximal esophagus and UES relaxation. A second observation is that those correlations differ among achalasia subtypes, which were absent in type I achalasia, but were reserved in type II and III achalasia.

Wauters et $\mathrm{al}^{7}$ first reported that balloon dilation of the LES affects intraesophageal and UES pressures in a cohort of 50 achalasia patients and pointed out that there is a neural feedback mechanism existing between the tension in the esophageal wall and UES relaxation. Interestingly, our findings suggest that endoscopic myotomy of distal EB instead of myotomy of LES significantly affects the contraction pressure of proximal esophagus and UES-RP. One possible mechanism is that the myotomy of distal esophagus seems to have an inhibition reflex on the motility of the proximal esophagus, mediated by the enteral nervous system. This could be illustrated by the manometric change of EB in type II achalasia, in which contraction of segments with and without myotomy attenuated synchronously and not separated as a whole. Another possible mechanism is reduced proximal venting resistance following myotomy of the distal segment of EB and LES, so that the proximal intraesophageal pressure including UES-RP was reduced according to distal myotomy. This mechanism could be demonstrated in type III achalasia, in which spasm of the proximal segment without 
Table 4. Bivariate Spearman Correlation Analysis of Motility Changes ( $\Delta$ change After Peroral Endoscopic Myotomy) Between Distal Segment of Esophageal Body With Myotomy, Proximal Segment of Esophageal Body Without Myotomy, and Upper Esophageal Sphincter in Achalasia Subtypes

\begin{tabular}{|c|c|c|c|c|}
\hline \multicolumn{3}{|c|}{ Items } & \multirow{2}{*}{$\begin{array}{c}\Delta \mathrm{CI}-\mathrm{PNM} \\
-0.200\end{array}$} & \multirow{2}{*}{$\begin{array}{c}\Delta \mathrm{UES}-\mathrm{RP} \\
0.224\end{array}$} \\
\hline$\Delta \mathrm{CI}-\mathrm{DM}$ & Type I & Correlation coefficient & & \\
\hline & & $P$-value & 0.704 & 0.219 \\
\hline & Type II & Correlation coefficient & 0.699 & 0.400 \\
\hline & & $P$-value & 0.002 & 0.112 \\
\hline & Type III & Correlation coefficient & 0.917 & 0.667 \\
\hline & & $P$-value & 0.001 & 0.050 \\
\hline \multirow[t]{6}{*}{$\Delta \mathrm{CI}-\mathrm{PNM}$} & Type I & Correlation coefficient & & -0.209 \\
\hline & & $P$-value & & 0.957 \\
\hline & Type II & Correlation coefficient & & 0.691 \\
\hline & & $P$-value & & 0.002 \\
\hline & Type III & Correlation coefficient & & 0.650 \\
\hline & & $P$-value & & 0.058 \\
\hline
\end{tabular}

CI-PNM, contractile integral of proximal segment without myotomy; UES-RP, relaxation pressure of upper esophageal sphincter; CI-DM, contractile integral of distal segment with myotomy.
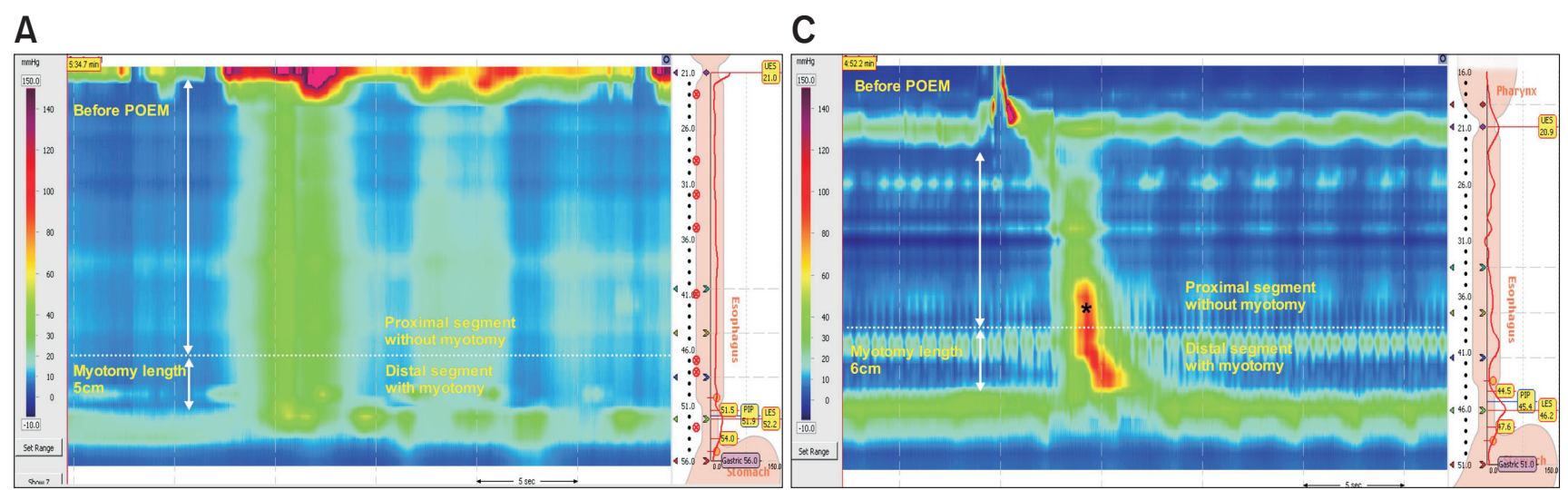

B

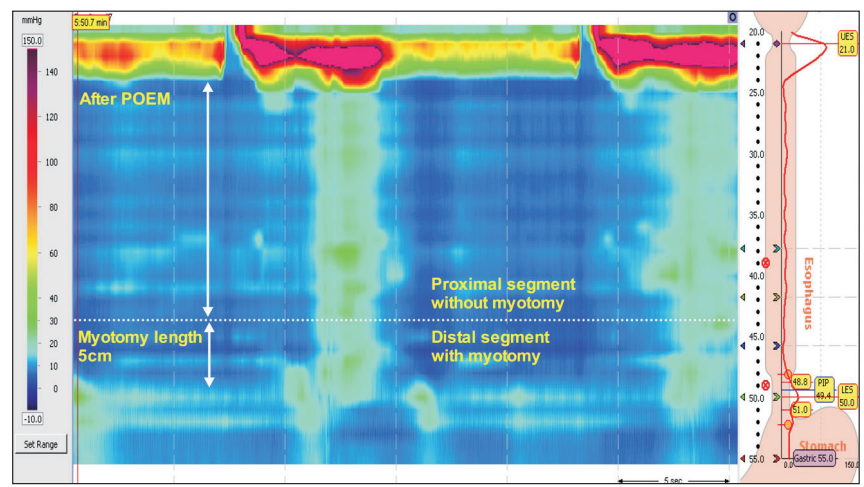

D

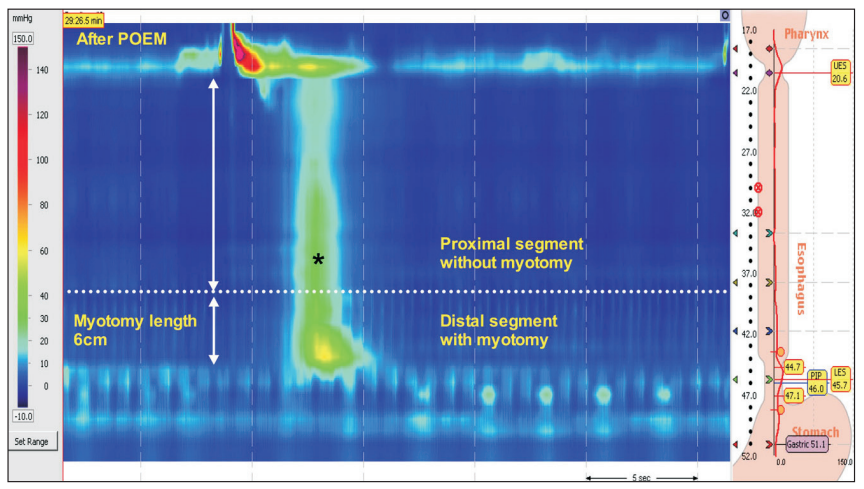

Figure 3. High-resolution manometric plot of the esophageal body before and after peroral endoscopic myotomy (POEM). (A) Type II achalasia before POEM in one patient. Pan-esophageal pressurization could be detected. The myotomy length was $5 \mathrm{~cm}$. (B) In the same patient after POEM, the pressurization of the proximal segment without myotomy attenuated with the pressurization of the distal segment with myotomy synchronously as a whole. (C) Type III achalasia before POEM in another patient. Distal esophageal spasm was noted. The myotomy length was 6 $\mathrm{cm}$. (D) After POEM in the same patient, the spasm in the proximal segment without myotomy (black asterisk) attenuated with the spasm in the distal segment with myotomy. 
myotomy disappeared with spasm in the distal segment with myotomy. Perhaps both mechanisms works in all subtypes of achalasia and inhibits the contraction or spasm of the EB and facilitate the relaxation of UES in achalasia patients.

The influence of distal myotomy on the motility of proximal esophagus has clinical significance. The simultaneous contraction or pressurization of the EB would impact the food bolus and cause dysphagia. Ren et $\mathrm{al}^{13}$ hypothesized that the simultaneous contraction of the EB would provide a "viscous resistance" to food bolus during swallow. Myotomy of the distal esophagus was found to significantly inhibit the pressurization of the whole EB and lead to less "viscous resistance." In addition, Dudnick et $\mathrm{al}^{14}$ found increased UES-RP in achalasia patients, suggesting that impaired UES relaxation might provide additional resistance to food bolus during swallow. POEM would additionally decrease UES resistance and facilitate the food swallows. Apart from expected decreased LES pressures, decreased esophageal contraction and UES-RP might benefit symptom improvement for achalasia patients.

This influence differs among achalasia subtypes according to the Chicago classification, which was absent in type I achalasia, but was preserved in type II and III achalasia. One possible explanation is the small sample size of type I achalasia patients included, so that false negative results could be inevitable. Another explanation is the $\mathrm{CI}$ of EB in type I achalasia is very low and the change of CI-DM and CI-PNM were insignificant for type I achalasia, so the correlation could be insignificant. Furthermore, it was suggested that type I achalasia is a later stage than type II and III achalasia because of progressive myenteric neuron loss. ${ }^{15}$ The inhibitory and excitatory neurons were eliminated in type I achalasia but were somehow preserved in type II and III achalasia. Since those motility changes were hypothesized to be a myenteric neuron-mediated reflex, it is least likely that those motility changes would occur with eliminated myenteric neurons, as in type I achalasia.

This finding could possibly guide the decision of the optimal myotomy length in POEM. The length of conventional Heller myotomy is largely empirical. Usually a longer myotomy at least $6 \mathrm{~cm}$ over the esophagus above the $\mathrm{GEJ}$ is recommended, ${ }^{16,17}$ especially for vigorous achalasia. In one recent POEM study for esophageal spastic disease including diffuse esophageal spasm, jackhammer esophagus, and type III achalasia, the myotomy length was set according to the proximal extent of hypertensive contractions and the longest length was $26 \mathrm{~cm}$ (range: $7-26 \mathrm{~cm}$ ). ${ }^{18}$ Nevertheless, in our previous unpublished study, there was no significant difference in symptom improvement or motility changes between long myotomy $(\geq 7 \mathrm{~cm})$ and short myotomy $(<7 \mathrm{~cm})$ in achalasia pa- tients. Long myotomy might need more time and would probably cause more complications such as perforation or pneumothorax. Based on this finding, we could postulate that shorter myotomy would also lead to satisfactory remission of pressurization or spasm in the proximal esophagus. Further studies should focus on finding the optimal short myotomy length in POEM, especially in type II and III achalasia.

This study has limitations. First, because achalasia has low prevalence and manometry is uncomfortable, we have a limited number of achalasia patients included and only short follow-up in our one single medical center. Type II error could possibly exist, especially in the type I and type III subgroups. Second, we did not set healthy control because the manometry data was analyzed objectively with software, which could be reproducible. Future studies should focuse on multi-centered larger sample size and longer follow-up.

In conclusion, peroral endoscopic myotomy of distal EB would decrease the proximal esophageal contraction pressure and UESRP.

\section{Supplementary Materials}

Note: To access the supplementary table mentioned in this article, visit the online version of Journal of Neurogastroenterology and Motility at http://www.jnmjournal.org/, and at http://dx.doi. org/10.5056/jnm15098.

Acknowlegements: The authors especially thank Yingying Zou of Nanfang Hospital for her contribution to this investigation.

Financial support: This study was supported by National Natural Science Foundation of China (Grant No. 81101610).

Conflicts of interest: None.

\section{References}

1. Ghosh SK, Pandolfino JE, Rice J,Clarke JO, Kwiatek M, Kahrilas PJ. Impaired deglutitive EGJ relaxation in clinical esophageal manometry: a quantitative analysis of 400 patients and 75 controls. Am J Physiol Gastrointest Liver Physiol 2007;293:G878-G885.

2. Vaezi MF, Pandolfino JE, Vela MF. ACG clinical guideline: diagnosis and management of achalasia. Am J Gastroenterol 2013;108:1238-1249.

3. Inoue H, Minami H, Kobayashi Y, et al. Peroral endoscopic myotomy (POEM) for esophageal achalasia. Endoscopy 2010;42:265-271.

4. Chiu PW, Wu JC, Teoh AY, et al. Peroral endoscopic myotomy for 
treatment of achalasia: from bench to bedside (with video). Gastrointest Endosc 2013;77:29-38.

5. Ling T, Guo H, Zou X. Peroral endoscopic myotomy is effective for achalasia patients with failure of prior pneumatic dilation: a prospective case-control study. J Gastroenterol Hepatol 2014;29:1609-1613.

6. Swanstrom LL, Kurian A, Dunst CM, Sharata A, Bhayani N, Rieder E. Long-term outcomes of an endoscopic myotomy for achalasia: the POEM procedure. Ann Surg 2012;256:659-667.

7. Wauters L, Van Oudenhove L, Selleslagh M, et al. Balloon dilation of the esophagogastric junction affects lower and upper esophageal sphincter function in achalasia. Neurogastroenterol Motil 2014;26:69-76.

8. Yao S, Linghu E. Peroral endoscopic myotomy can improve esophageal motility in patients with achalasia from a large sample self-control research (66 patients). PLoS One 2015;10:e125942.

9. Pandolfino JE, Kwiatek MA, Nealis T, Bulsiewicz W, Post J, Kahrilas PJ. Achalasia: a new clinically relevant classification by high-resolution manometry. Gastroenterology 2008;135:1526-1533.

10. Kahrilas PJ, Bredenoord AJ, Fox M, et al. The Chicago classification of esophageal motility disorders, v3.0. Neurogastroenterol Motil 2015;27: 160-174.

11. Bredenoord AJ, Fox M, Kahrilas PJ, et al. Chicago classification criteria of esophageal motility disorders defined in high resolution esophageal pressure topography. Neurogastroenterol Motil 2012;24(suppl 1):57-65.

12. Eckardt VF, Aignherr C, Bernhard G. Predictors of outcome in patients with achalasia treated by pneumatic dilatation. Gastroenterology 1992;103:1732-1738.

13. Ren Y, Ke M, Fang X, et al. Response of esophagus to high and low temperatures in patients with achalasia. J Neurogastroenterol Motil 2012;18:391-398.

14. Dudnick RS, Castell JA, Castell DO. Abnormal upper esophageal sphincter function in achalasia. Am J Gastroenterol 1992;87:1712-1715.

15. Kahrilas PJ, Boeckxstaens G. The spectrum of achalasia: lessons from studies of pathophysiology and high-resolution manometry. Gastroenterology 2013;145:954-965.

16. Ali A, Pellegrini CA. Laparoscopic myotomy: technique and efficacy in treating achalasia. Gastrointest Endosc Clin N Am 2001;11:347-358, vii.

17. Rohof WO, Salvador R, Annese V, et al. Outcomes of treatment for Achalasia depend on manometric subtype. Gastroenterology 2013;144: 718-725.

18. Khashab MA, Messallam AA, Onimaru M, et al. International multicenter experience with peroral endoscopic myotomy for the treatment of spastic esophageal disorders refractory to medical therapy (with video). Gastrointest Endosc 2015;81:1170-1177. 